\title{
Incorporating Deposit Ageing into Visualisation of Crude Oil Preheat Train Fouling
}

\author{
E.M. Ishiyama ${ }^{1} \cdot$ S.J. Pugh ${ }^{1} \cdot$ D.I. Wilson ${ }^{2}$ (B)
}

Received: 10 September 2019/Revised: 4 December 2019 / Accepted: 30 December 2019 / Published online: 7 February 2020

(C) The Author(s) 2020

\begin{abstract}
Fouling is an acute problem in crude oil preheat train heat exchangers as it affects the thermal and hydraulic performance of individual units as well as the network. Ageing of fouling deposits complicates these interactions and effective tools for visualising these effects are needed. The modified temperature field plot construction, devised by Graham Polley and coworkers in 2002, allows the impact of fouling on pressure drop and heat duty across individual units and the preheat train to be presented in a systematic way. The simple deposit ageing model of Ishiyama et al. (AIChEJ 56:531-545, 2010a) was incorporated into the analysis of a simple preheat train based on that presented by Panchal and Huang-Fu (Heat Transfer Eng 21:3-9, 2000) to calculate the impact of ageing on fouling dynamics and network performance. The modified temperature field plot is shown to be effective in communicating the impact of fouling and ageing, allowing a designer or operator to be able to interpret correctly what might otherwise be conflicting trends or unexpected behaviour.
\end{abstract}

Keywords Ageing $\cdot$ Fouling $\cdot$ Network $\cdot$ Pressure drop

\section{Introduction}

Crude oil distillation is the backbone of any oil refinery. Distillation is an energy-intensive process and recovery of thermal energy from distillation products to the crude oil feed in a preheat train network is essential for economic operation. Many crudes and crude blends, however, promote fouling in the network exchangers, reducing the amount of heat transferred and

Highlights

- Ageing can switch the main impact of fouling from duty loss to pressure drop.

- The modified temperature field plot is an effective way of presenting the thermal and hydraulic performance of the network.

- The plot allows the designer or operator to understand fouling impacts and assess mitigation options.

Electronic supplementary material The online version of this article (https://doi.org/10.1007/s41660-019-00104-8) contains supplementary material, which is available to authorized users.

D.I. Wilson

diw11@cam.ac.uk

1 formerly IHS Downstream Research, 133 Houndsditch, London EC3A 7BX, UK

2 Department of Chemical Engineering and Biotechnology, University of Cambridge, Philippa Fawcett Drive, Cambridge CB3 0AS, UK increasing pressure drops which can limit throughput (Polley et al. 2009). Since crude distillation units (CDUs) are required to run continuously for periods of up to several years, fouling is often countered through a series of fouling mitigation options such as the use of antifouling chemicals, periodic removal of individual exchangers for cleaning, etc. A list of fouling mitigation options used in crude preheat trains are discussed in Ishiyama et al. (2020).

Optimisation of cleaning schedules for CDU network exchangers has received considerable attention over the last 10 years (e.g. Rodriguez and Smith (2007); Ishiyama et al., 2009, Ishiyama et al., 2010b); Liu et al. (2015); Diaby et al. (2016); Diaz-Bejarano et al. (2016)), building on the development of quantitative models for predicting the rate of fouling in different exchangers, as reviewed by Wilson et al. (2017).

Optimising cleaning operations reduces the impact of fouling on performance, but it represents a method for coping with fouling rather than reducing the likelihood of fouling occurring. Graham Polley was one of the first workers to recognise the opportunity that quantitative predictive fouling models, such as that by Ebert and Panchal (1997), offered in terms of designing CDU preheat trains and individual CDU exchangers to reduce the extent of fouling and even prevent it occurring in certain units. His first paper on the topic (Wilson et al. 2002) combined 
Ebert and Panchal's quantitative model for predicting the rate of crude oil fouling with the temperature field plot, a graphical construction illustrating the matching of process streams with the cold crude. The Ebert and Panchal model allowed operating conditions (surface temperature, crude flow velocity) which would give low fouling rates to be identified. These 'fouling thresholds' were added to the temperature field plot (TFP) so that optimal use of available pressure drop could be identified, both in green field design and revamping of existing networks. This approach allowed the maximum feasible heat recovery for a CDU to be determined, i.e. with manageable amounts of fouling and cleaning (Polley et al. 2002a; Polley et al. 2005).

Polley and co-workers subsequently extended the field plot to incorporate considerations of the impact of fouling on pressure drop (Yeap et al. 2004) and therefore unit throughput. Maintaining throughput is usually critical to the operation of CDUs: losses in heat transfer performance can be accommodated by extra furnace duty, but large pressure drops can result in the crude partially vapourising in exchangers upstream of the furnace (or in some cases upstream of the preflash for networks where preflash columns are employed) as its pressure decreases and bulk temperature increases (Ishiyama and Pugh 2015). Using first order models, they linked the thermal and hydraulic effects of fouling: they considered shell-and-tube exchangers as this configuration is the most common type used on refineries. Depending on the operating philosophy of the refinery, crude (or the higher fouling stream) may be allocated on the tubeside to facilitate easier cleaning. However, it is acknowledged that this is not always the case.

In this paper we revisit the modified temperature field plot to incorporate some of the developments made since 2004, many of which were inspired by Graham Polley's insight into the practical implications of fouling on CDU design and operation. Graham was a strong advocate of visualisation tools: the modified temperature field plot allows the user to assess at a glance the impact of fouling on the thermo-hydraulic performance of an exchanger and a network, and thus represents an important way of communicating this to the operators of such networks as well as designers looking at revamping, retrofitting and creating networks. The particular focus is on deposit ageing, which can introduce unexpected dynamics into preheat train performance.

Other workers have developed higher order models and more complex simulation tools (e.g. Coletti et al. 2011; Diaz-Bejarano et al. 2016) which capture the dynamics of fouling and its impact on preheat train performance in greater detail. Effective presentation of that information in a coherent form remains an issue, as with other complex calculations, and the modified temperature field plot remains, in the authors' opinion, a versatile tool for this. Moreover, it can be used to present the results from complex simulations.

\section{Quantifying the Impact of Fouling-the Modified Temperature Field Plot}

The thermal effect of fouling is often quantified in terms of the fouling resistance, $R_{\mathrm{f}}$, defined as the difference between the overall heat transfer coefficient, $U$, and its value when clean, $U_{\mathrm{o}}$ :

$R_{\mathrm{f}}=\frac{1}{U}-\frac{1}{U_{\mathrm{o}}}$

This can be written as

$U=\frac{U_{\mathrm{o}}}{1+R_{\mathrm{f}} U_{\mathrm{o}}}=\frac{U_{\mathrm{o}}}{1+B i_{\mathrm{f}}}$

where $B i_{\mathrm{f}}$ is the fouling Biot number. Fouling affects pressure drop by changing the roughness of the surface and by narrowing the flow channel, i.e. reducing the inner diameter of a tube in the case of tubeside fouling. For the case of a single phase liquid operated at constant flow rate in the turbulent regime, the ratio of the pressure drop across a tube with inner diameter $d_{\mathrm{i}}$ and fouling layer of thickness $\delta$ to that of the clean tube, $\Delta P^{*}$, is given by (Yeap et al. 2004)

$\Delta P^{*} \approx \frac{1}{\left(1-2 \delta / d_{\mathrm{i}}\right)^{5}}$

If the fouling layer is thin and uniform, it can be treated as a thin slab. Yeap et al. showed that this is likely to apply in cases of chronic fouling in CDUs, which is the subject of this work. The fouling resistance can be related to the deposit thickness via

$R_{\mathrm{f}}=\frac{\delta}{\lambda_{\mathrm{c}}}$

where $\lambda_{\mathrm{c}}$ is the deposit thermal conductivity. Equation [3] can then relate the thermal and hydraulic effects of fouling, viz.

$\Delta P^{*} \approx\left(1-2 \lambda_{\mathrm{c}} B i_{\mathrm{f}} / U_{\mathrm{o}} d_{\mathrm{i}}\right)^{-5}$

In this expression, $U_{\mathrm{o}}$ and $d_{\mathrm{i}}$ are set by the design and operation of the heat exchanger. The deposit thermal conductivity is a material parameter, which is subject to substantial uncertainty. Crude oil deposits vary in composition (oil, metal oxides, carbonaceous material; Derakshesh et al. 2013) and $\lambda_{\mathrm{c}}$ is expected to lie in the range $0.2 \mathrm{~W} \mathrm{~m}^{-1} \mathrm{~K}^{-1}<\lambda_{\mathrm{c}}<$ $3 \mathrm{~W} \mathrm{~m}^{-1} \mathrm{~K}^{-1}$ (Watkinson and Wilson 1997; Derakshesh et al. 2013; Ishiyama et al. 2020). The impact of this uncertainty is demonstrated in Fig. 1, which shows the effect of thermal conductivity on the relationship between $B i_{\mathrm{f}}$ (and heat transfer performance) and $\Delta P^{*}$ (and throughput) calculated for a simple countercurrent heat exchanger with $U_{\mathrm{o}}$ and $d_{\mathrm{i}}$ values typical of those employed on CDU units (Panchal and Huang-Fu 2000; Yeap et al. 2004). The range of $B i_{\mathrm{f}}$ and 


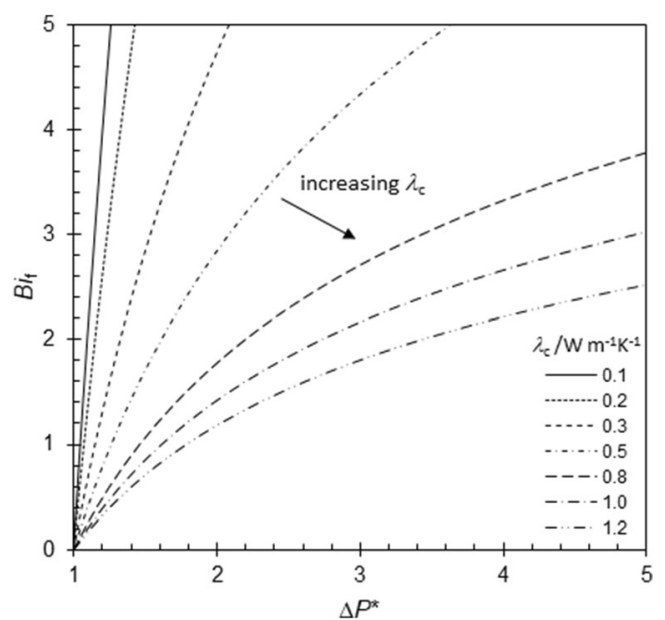

Fig. 1 Effect of deposit thermal conductivity on thermo-hydraulic performance of simple countercurrent heat exchanger. Equation [5] plotted for the case where $U_{\mathrm{o}}=1000 \mathrm{~W} \mathrm{~m}^{-2} \mathrm{~K}^{-1}, d_{\mathrm{i}}=22 \mathrm{~mm}$

$\Delta P^{*}$ values extends beyond those likely to be acceptable in practice.

It can be seen that as the thermal conductivity of the deposit increases, the relationship between the thermal and hydraulic effects change. Equation [4] shows that a deposit with a high thermal conductivity has a smaller effect on heat transfer. This has implications for preheat train operation, because whereas a loss in heat recovery can be countered by an increase in furnace duty (until a firing limit is reached), increasing pressure drop will eventually result in a reduction in throughput or flashing of the crude which is not so easily compensated for.

Equation [5] allows hydraulic considerations to be included alongside thermal ones in the modified temperature field plot (MTFP) and a brief explanation of the MTFP is given here. Figure 2 shows a schematic MTFP, where the abscissa is the crude oil bulk temperature, $T_{\mathrm{b}}$. The crude-side heat transfer surface temperature, $T_{\mathrm{s}}$, or film temperature, $T_{\mathrm{f}}$, is plotted on the primary ordinate axis, depending on which is the key parameter affecting deposition. An exchanger is then plotted as a line linking the values at the crude inlet and outlet. $T_{\mathrm{b}}$ also serves as a measure of heat duty as the crude is usually liquid throughout the train and its specific heat does not vary strongly with temperature.

The surface temperature, $T_{\mathrm{s}}$, is often a key variable in quantitative models for calculating the fouling rate. The original work by Polley and colleagues considered the 'threshold fouling' model of Ebert and Panchal (1997), where the rate of change of fouling resistance (the 'fouling rate') on the crudeside was expressed in terms of a competition between a growth term and a suppression term, viz.

$\frac{d R_{\mathrm{f}}}{d t}=k_{\mathrm{f}} v^{m} \exp \left(-\frac{E_{\mathrm{f}}}{R T_{\mathrm{s}}}\right)-b \tau_{\mathrm{w}}$

where $t$ is time, $v$ the bulk mean velocity, $R$ the gas constant and $k_{\mathrm{f}}, b, E_{\mathrm{f}}$ and $m$ are model parameters. $\tau_{\mathrm{w}}$ is the

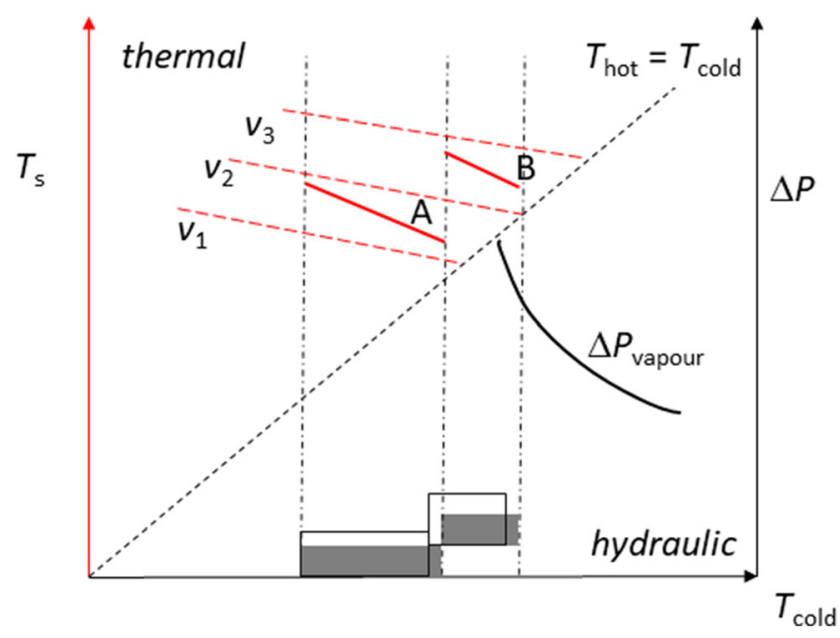

Fig. 2 Schematic of modified temperature field plot. Upper quadrant: dashed lines labelled $v_{\mathrm{i}}$ show fouling threshold for velocity $v$. Solid lines indicate heat exchanger matches. Lower quadrant: bold line shows vapourisation threshold. Grey boxes indicate clean pressure drop, open boxes pressure drop across a fouled exchanger after a given operating time, e.g. $t_{\mathrm{op}}$

shear stress exerted by the flowing crude on the heat transfer (and subsequently the deposit) surface. The RHS of Eq. [6] suggests that the fouling rate will be small or zero for some combination of $T_{\mathrm{s}}, T_{\mathrm{b}}$ and $v$ (as $\tau_{\mathrm{w}}$ is determined primarily by $v$ ). This is the 'threshold fouling' concept introduced by Ebert and Panchal. It should be noted that negative fouling rates are not valid (shear-driven removal of a mature CDU deposit is seldom observed in practice). On the MTFP, loci are calculated for a set value of the fouling rate, i.e. zero or a value unlikely to give rise to significant change in performance over the desired operating period, as shown on Fig. 2 where $v_{1}<v_{2}<v_{3}$. This allows the designer to identify matches which would cross one of the loci and therefore set the lowest allowable tubeside velocity to use in that unit.

Graham Polley published several papers on kinetic models for describing crude oil fouling (e.g. Polley et al. 2002b; Polley et al. 2007). Given the lack of laboratory experimental data, owing to the cost and complexity of conducting such experiments, he worked on different approaches to dealing with plant data, with a noteworthy emphasis on generating forms that could be used in practice for design or operation of units. His work on utilising fouling prediction models to predict performances of crude preheat trains and furnaces has been presented elsewhere (Ishiyama et al. 2012a, 2012b, 2011; Kumana et al. 2010; Morales-Fuentes et al. 2011; Polley et al. 2013, 2011b, 2011a). The case study presented here employs the asphaltene precipitation model (APM) which he proposed (see Ishiyama et al. (2013)), where

$\frac{d R_{\mathrm{f}}}{d t}=\frac{k_{\mathrm{f}, \mathrm{APM}}}{h} \exp \left(-\frac{E_{\mathrm{f}}}{R \mathrm{~T}_{\mathrm{f}}}\right)\left(1-\left(\frac{\tau_{\mathrm{w}}-2}{c}\right)^{\frac{1}{2}}\right) \quad \tau_{\mathrm{w}} \geq 2 \mathrm{~Pa}$ 
Table 1 Thermal conductivity of carbonaceous fouling deposits. Values reported are at $15^{\circ} \mathrm{C}$, unless otherwise stated

\begin{tabular}{|c|c|c|}
\hline Deposit & 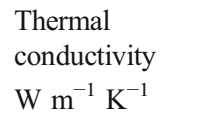 & Source \\
\hline Delayed coking furnace deposit & 0.03 & Derakshesh et al. (2013) \\
\hline Coke flakes & $0.07-0.15$ & Nelson (1939) \\
\hline Ash deposits & 0.11 to 0.17 & Robinson et al. (2001) \\
\hline Jet fuel foulant deposit & 0.12 & Evans (1968) \\
\hline $\begin{array}{l}\text { Crude preheat train deposits based on pressure drop } \\
\text { data }\end{array}$ & 0.1 to 1 & Ishiyama et al. (2020) \\
\hline Combustion chamber deposits & 0.17 to 0.8 & Weidenlener et al. (2018) \\
\hline Combustion chamber deposits & 1.5 & Güralp (2008) \\
\hline Coke-like deposit & $0.5-1$ & Watkinson (1988) \\
\hline Amorphous to condensed coke & 0.55 to 76 & Fan (2006) \\
\hline Coke deposit (from pyrolysis unit) & $1-4$ & Maksimovskii et al. (1990) \\
\hline Graphite powder & 1.8 & Perry and Green (2007) \\
\hline Carbon nano fibres & 3 to 10 & $\begin{array}{l}\text { Mayhew and Prakash } \\
\text { (2013) }\end{array}$ \\
\hline Petroleum coke & 5.8 (at $100{ }^{\circ} \mathrm{C}$ ) & Kern (1957) \\
\hline Carbon deposited at $2100{ }^{\circ} \mathrm{C}$ & $\begin{array}{l}5.6\left(\text { at } 50{ }^{\circ} \mathrm{C}\right) \\
4.9\left(\text { at } 200{ }^{\circ} \mathrm{C}\right)\end{array}$ & Brown et al. (1956) \\
\hline at $2000{ }^{\circ} \mathrm{C}$ & $\begin{array}{l}4.6\left(\text { at } 50{ }^{\circ} \mathrm{C}\right) \\
4.2\left(\text { at } 200{ }^{\circ} \mathrm{C}\right)\end{array}$ & \\
\hline at $1900{ }^{\circ} \mathrm{C}$ & $\begin{array}{l}0.89\left(\text { at } 50{ }^{\circ} \mathrm{C}\right) \\
0.97\left(\text { at } 200{ }^{\circ} \mathrm{C}\right)\end{array}$ & \\
\hline at $1800{ }^{\circ} \mathrm{C}$ & $\begin{array}{l}0.27\left(\text { at } 50{ }^{\circ} \mathrm{C}\right) \\
0.32\left(\text { at } 200{ }^{\circ} \mathrm{C}\right)\end{array}$ & \\
\hline Commercial graphite & $\begin{array}{l}0.89\left(\text { at } 50{ }^{\circ} \mathrm{C}\right) \\
0.89\left(\text { at } 200{ }^{\circ} \mathrm{C}\right)\end{array}$ & \\
\hline
\end{tabular}

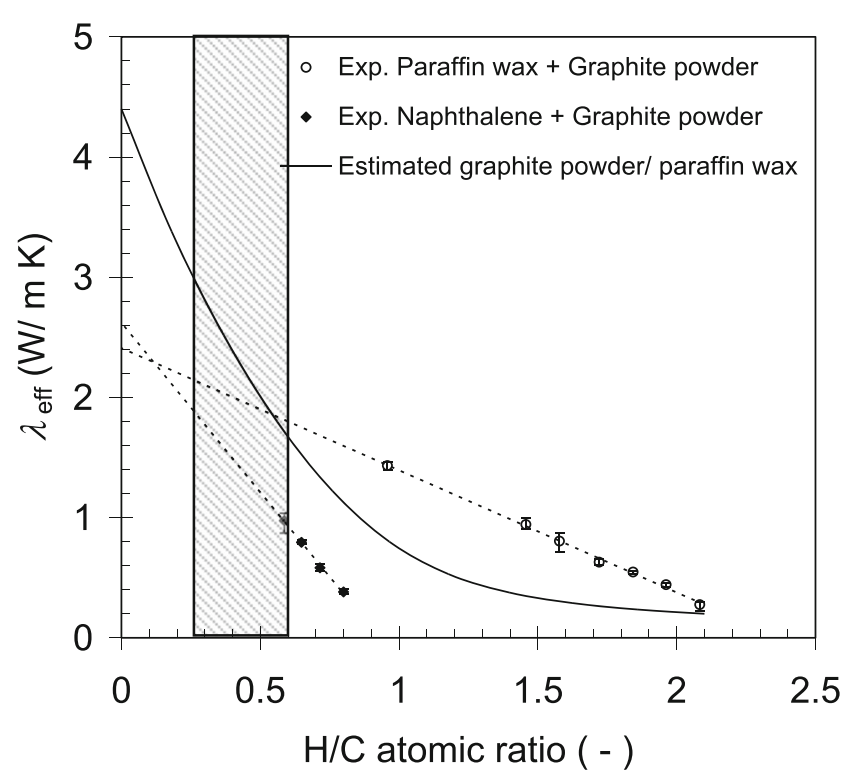

Fig. 3 Effective thermal conductivity estimated for graphite powder/ paraffin wax mixtures (solid line) and experimental measurements of mixtures of graphite powder and naphthalene (solid symbols) and paraffin wax (open symbols), after Wilson et al. (2009). The shaded region indicates the range of $\mathrm{H} / \mathrm{C}$ ratios reported by Fan and Watkinson (2006) $\frac{d R_{\mathrm{f}}}{d t}=\frac{k_{\mathrm{f}, \mathrm{APM}}}{h} \exp \left(-\frac{E_{\mathrm{f}}}{R \mathrm{~T}_{\mathrm{f}}}\right) \quad \tau_{\mathrm{w}}<2 \mathrm{~Pa}$

Here $h$ is the film heat transfer coefficient for the crude stream, $T_{\mathrm{f}}$ is the film temperature and $k_{\mathrm{f}, \mathrm{APM}}$ is a constant specific to the crude. $c$ is set at $98 \mathrm{~Pa}$ based on field

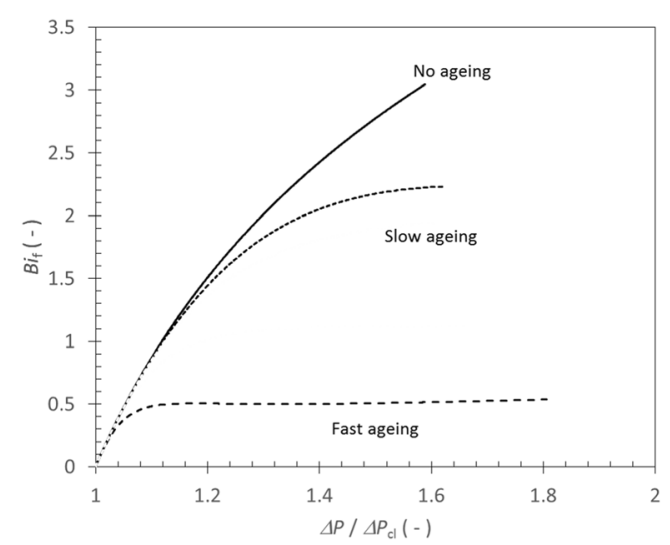

Fig. 4 Thermo-hydraulic impact of fouling for an exchanger subject to severe fouling (Eq. [5]) with (i) no ageing - constant thermal conductivity, $\lambda_{\mathrm{c}}=0.2 \mathrm{~W} \mathrm{~m}^{-1} \mathrm{~K}^{-1}$; (ii) slow ageing; and (iii) fast ageing, both with $\lambda_{\mathrm{c}}$ changing from 0.2 to $2.0 \mathrm{~W} \mathrm{~m}^{-1} \mathrm{~K}^{-1}$ 


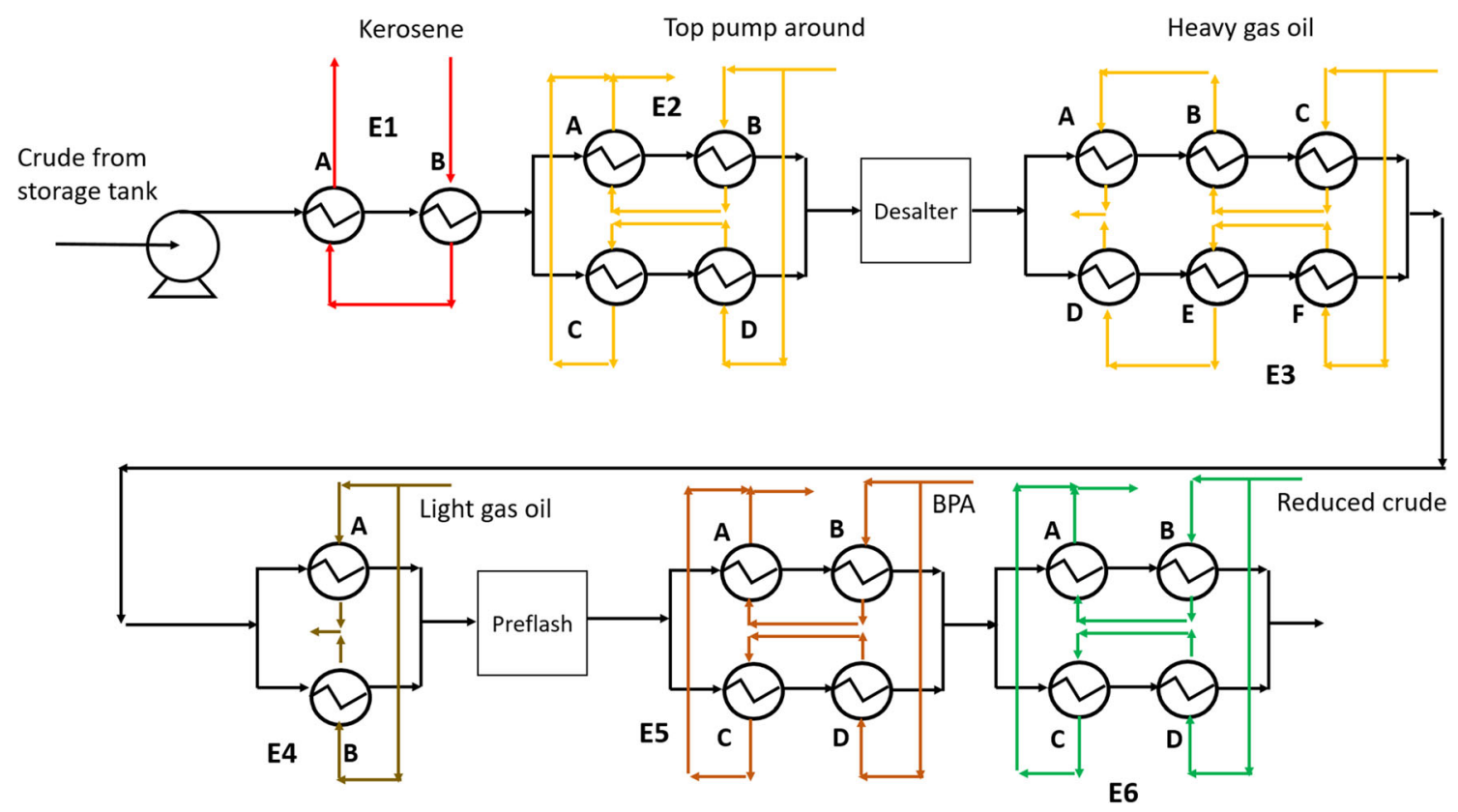

Fig. 5 Case study preheat train model based on Panchal and Huang-Fu (2000). Label Ei indicates a group of exchangers, with individual units labelled A, B, etc. Exchanger parameters, flow rates, temperatures are given in Tables 2 and 3

experience. The form of the APM was developed for shell and tube devices: application to other geometries (e.g. compact heat exchangers) has yet to be established.

The APM does not predict a zero fouling rate so a threshold fouling rate needs to be specified, which is a design parameter. Here we use a fouling rate based on the uncertainty in $U$ measurements based on plant data, and the timescale of the operation, e.g. the duration between shut-downs, $t_{\mathrm{op}}$. A typical uncertainty (Mohanty 2012) is 10\%, which yields the following criterion from Eq. [2]

$$
\left(\frac{d R_{\mathrm{f}}}{d t}\right)_{\text {threshold }}=\frac{\Delta R_{\mathrm{f}}}{\Delta t}=\frac{1}{9 U_{\mathrm{o}}} \frac{1}{t_{\mathrm{op}}}
$$

with $U_{\mathrm{o}}$ being the clean heat transfer coefficient either for each exchanger, or for one at the hot end of the preheat train where fouling is expected to be fast (from Eq. [7]).

The above construction occupies the upper diagonal of the TFP. In the modified TFP, the lower quadrant is used to present the hydraulic performance of the exchanger. Given its geometry and $v$, the tubeside pressure drop can be estimated. This is plotted as a box in the lower diagonal, with pressure drop as the secondary ordinate and $T_{\mathrm{b}}$ as before. The boxes form a set of steps and identify where the allowable pressure drop is allocated. Moreover, when fouling is not zero, the impact of fouling on the tubeside pressure drop can be estimated from Eq. [5] and the box replotted. Exchangers which lie above the threshold for their tubeside velocity (or shear stress) will see an increase in the overall pressure drop over time. Similarly, the change in $U$ as a result of fouling can result in a reduction in the heat duty, so the length of the box changes. These points are illustrated in Fig. 2.

The calculations linking thermal and hydraulic performance require the timescale, $t_{\mathrm{op}}$, which is a design variable, and the deposit thermal conductivity. Data on fouling deposit thermal conductivities are sparse and Table 1 summarises those which the authors have found from a search of the literature. It can be seen that there is considerable
Table 2 Case study heat exchanger tubeside geometries (per shell). The shell-side exchanger geometries were not reported. Fixed heat transfer coefficients, which differ from those in Panchal and Huang-Fu (2000), were used on the shell-side

\begin{tabular}{lllllll}
\hline & E1 & E2 & E3 & E4 & E5 & E6 \\
\hline Number of tubes per shell & 916 & 1256 & 907 & 911 & 1288 & 1464 \\
Tube internal diameter $(\mathrm{cm})$ & 2.11 & 2.11 & 2.11 & 2.11 & 2.11 & 2.11 \\
Number of tubeside passes & $4^{\mathrm{a}}$ & $4^{\mathrm{b}}$ & $4^{\mathrm{b}}$ & $4^{\mathrm{b}}$ & $4^{\mathrm{b}}$ & $4^{\mathrm{b}}$ \\
Internal heat transfer area $\left(\mathrm{m}^{2}\right)$ & 208 & 1152 & 208 & 523 & 1478 & 1344 \\
Shell-side heat transfer coefficient $\left(\mathrm{W} \mathrm{m}^{-2} \mathrm{~K}^{-1}\right)$ & 1000 & 2510 & 300 & 300 & 300 & 300 \\
Flow area $\left(\mathrm{m}^{2}\right)$ & 0.160 & 0.220 & 0.159 & 0.159 & 0.225 & 0.256 \\
\hline
\end{tabular}

${ }^{\text {a }}$ This exchanger had 1 tube-pass in the original paper

${ }^{\mathrm{b}}$ These exchangers had 2 tube-passes in the original paper 
Table 3 Case study stream inlet conditions

\begin{tabular}{llll}
\hline Stream & Flow rate & Inlet temperature \\
\cline { 3 - 4 } & & $\begin{array}{l}\text { Panchal and Huang-Fu (2000) } \\
{ }^{\circ} \mathrm{C}\end{array}$ & $\begin{array}{l}\text { This work } \\
{ }^{\circ} \mathrm{C}\end{array}$ \\
\hline Crude & 136 & 20 & 20 \\
TPA & 265 & 336 & 170 \\
Kerosene & 15.2 & 226 & 226 \\
LGO & 36 & 299 & 280 \\
HGO & 108 & 371 & 310 \\
BPA & 104 & 299 & 320 \\
Residue & 68 & 374 & 340 \\
\hline
\end{tabular}

variation in the values so there is a need for more measurements of this thermophysical property. The low value reported by Derakshesh et al. (2013) arises from the measurements being made with a heated wire operating at constant heat flux, which promoted vapourisation of the oil in the porous deposit matrix. Equation [4] indicates that this would increase the insulating nature of the deposit significantly. Vapourisation of the crude also gives rise to large pressure drops and this gives rise to an additional locus on the MTFP, which is the total pressure drop and temperature at which vapourisation would occur. A generic locus is plotted on Fig. 2: the relationship is determined by the composition of the crude and the hydraulic configuration (including the pump characteristic) of the preheat train.

\section{Deposit Ageing}

One aspect of fouling behaviour which has not been considered in the temperature field plot construction to date is deposit ageing, where the thermal and mechanical properties of the foulant change over time. Ageing has been considered in detailed simulations (Diaz-Bejarano et al. 2016). At the

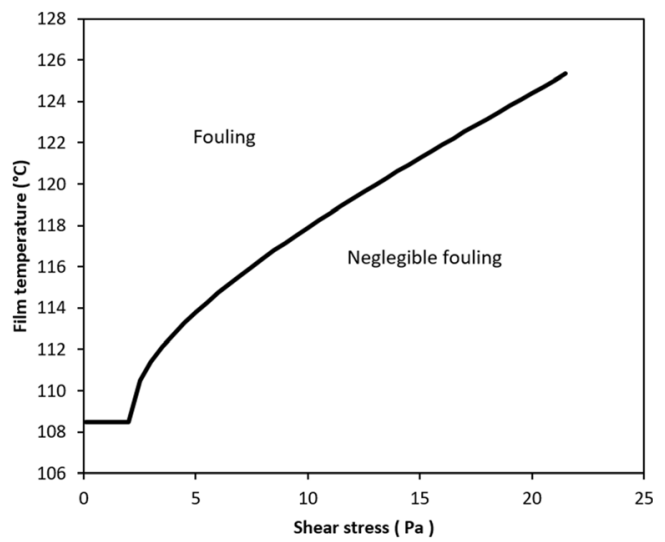

Fig. 6 Fouling threshold plot calculated for APM (Eq. [7], with $h=$ $1500 \mathrm{~W} \mathrm{~m}^{-2} \mathrm{~K}^{-1}, k_{\mathrm{f}, \mathrm{APM}}=50 \mathrm{~h}^{-1}$ ). Threshold given by Eq. [8], where 'no fouling' corresponds to $R_{\mathrm{f}}<5 \times 10^{-4} \mathrm{~m}^{2} \mathrm{~K} \mathrm{~W}^{-1}$ after 2 years of operation

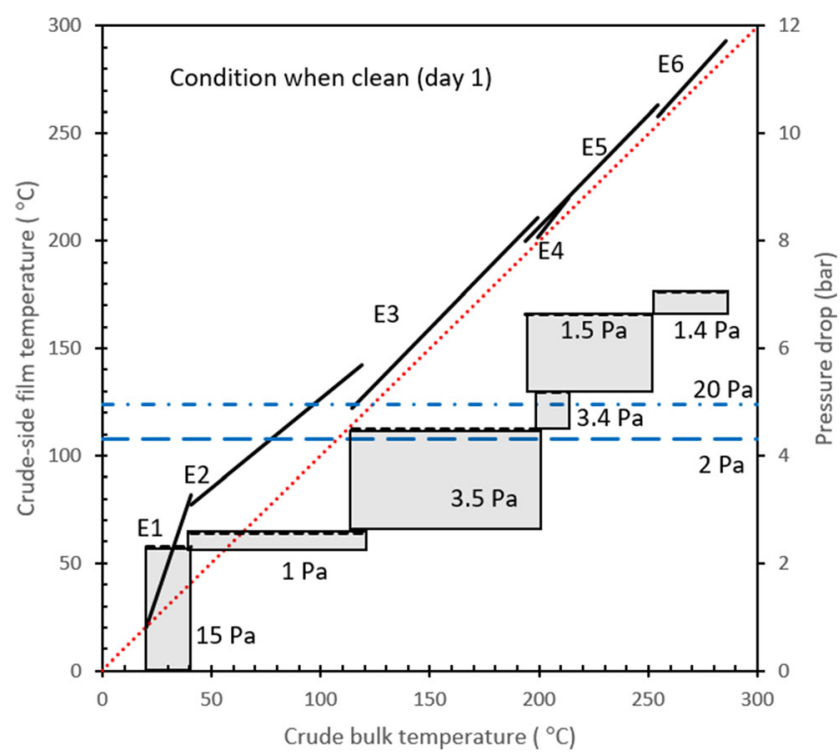

Fig. 7 Modified temperature field plot for the case study network when clean. Diagonal dashed line is the line of equality, i.e. $T_{\mathrm{f}}=T_{\mathrm{b}}$. Exchangers are plotted as solid lines (thermal performance) and boxes (pressure drop), the latter labelled with the average tubeside shear stress. Horizontal dashed lines show the fouling threshold condition

temperatures encountered at the heat transfer surface, the deposit is transformed from its original structure to one resembling coke. The effect on $\lambda_{\mathrm{c}}$ is shown by the experimental data for mixtures of wax and carbon black, representing two limiting cases, in Fig. 3. This is usually accompanied by a change in mechanical strength, which affects the selection of cleaning method.

Ageing is therefore important for CDU preheat trains, where units can be operated for several years between maintenance and cleaning actions. Ageing changes the relationship between the thermal and hydraulic performance of the exchanger. Equation [2] shows that increasing $\lambda_{\mathrm{c}}$ will reduce $R_{\mathrm{f}}$ but not $\Delta P^{*}$, so that the hydraulic impact cannot be reliably gauged from heat transfer measurements. In the worst case, vapourisation will occur as the total pressure drop rises while the crude temperature remains quite high. Studies reporting deposit ageing in CDUs have been reported by Ishiyama et al. (2020), while quantitative approaches for modelling ageing

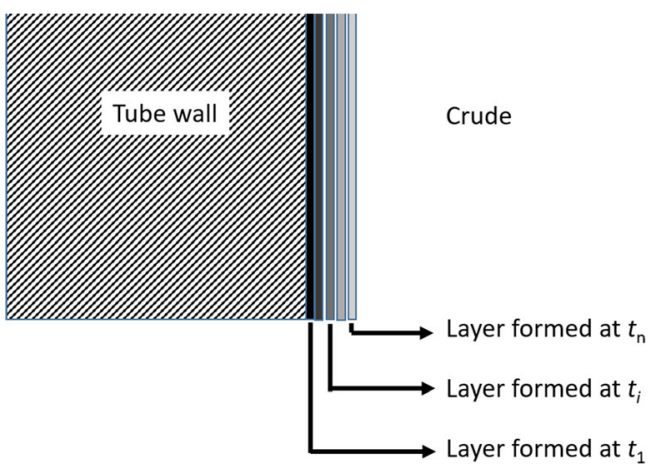

Fig. 8 Deposit ageing: schematic of deposit layers with different ages formed on the tube wall. $t_{\mathrm{i}}$ denotes the $i$ th time step 


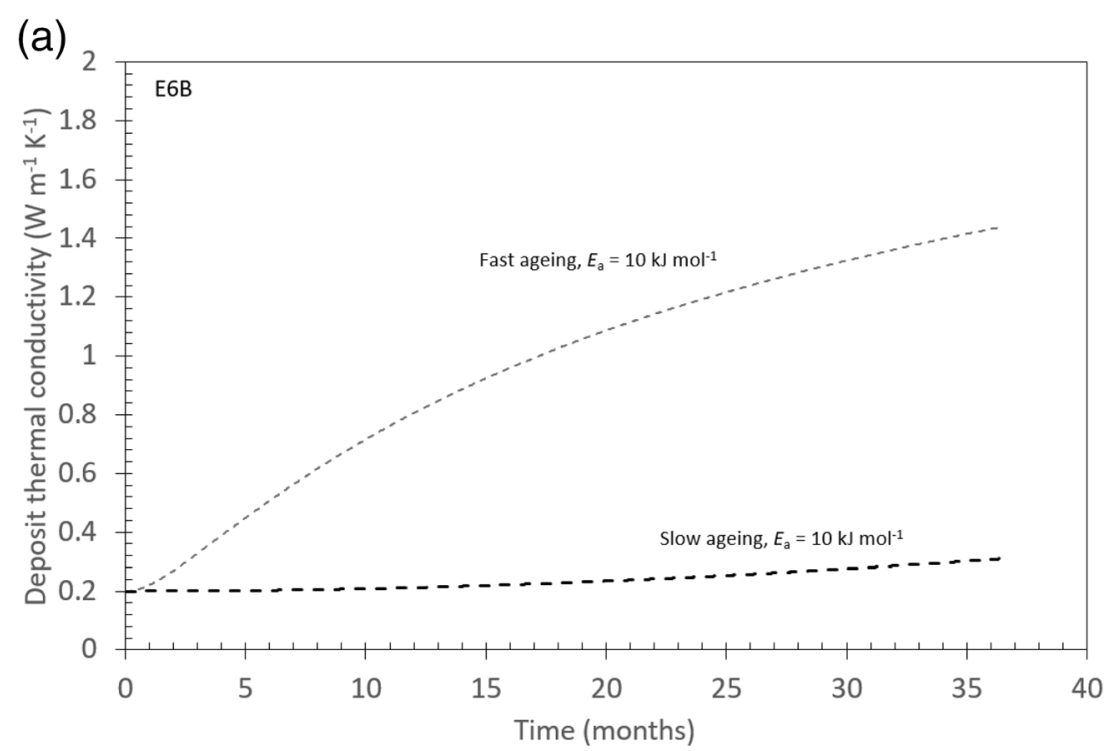

(b)

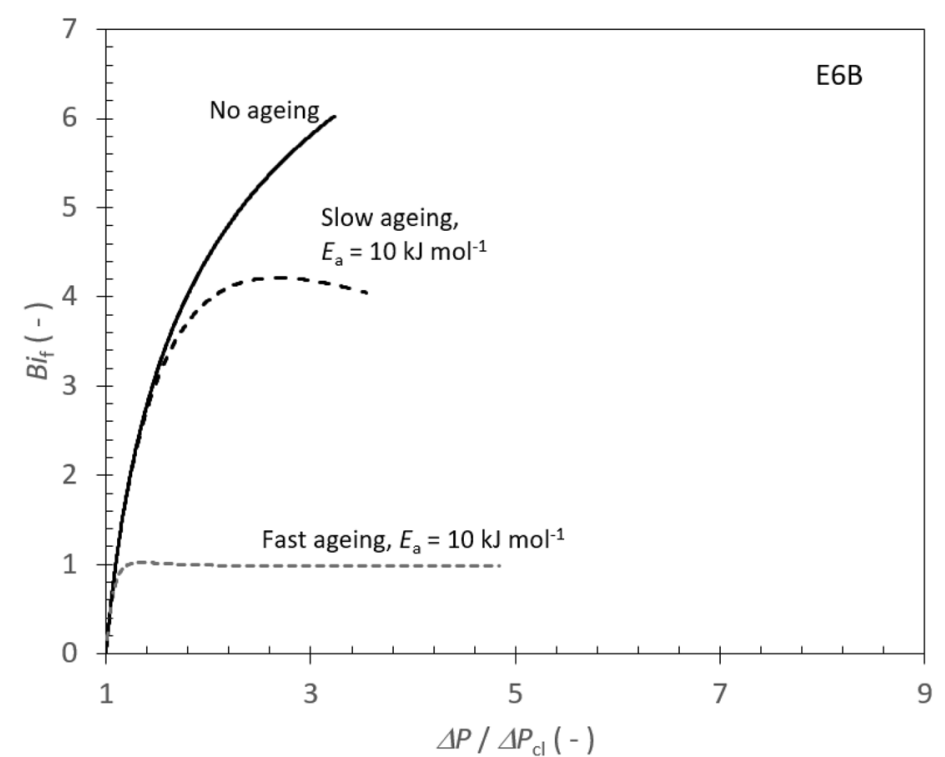

Fig. 9 Evolution of a effective deposit thermal conductivity and $\mathbf{b}$ thermo-hydraulic performance in case study exchanger E6B for fast and slow ageing with weak temperature dependency

have been presented by Ishiyama et al. (2010c, 2014a) and Coletti et al. (2010) Experimental studies of ageing to date have focussed on crystallisation (Brahim et al. 2003) and food (Davies et al. 1997) applications.

Incorporating ageing into the MTFP requires a quantitative model and here we use the first model on the topic, presented by Ishiyama et al. (2010c). This assumes a linear dependence of $\lambda_{\mathrm{c}}$ on an ageing parameter, the youth factor $y$, where $0<y \leq$ 1 , viz.

$\lambda_{\mathrm{c}}=\lambda_{\mathrm{c}, \infty}+y\left(\lambda_{\mathrm{c}, 0}-\lambda_{\mathrm{c}, \infty}\right)$

with $y$ initially set at 1 . The change in $y$ follows a first order kinetic law $\frac{d y}{d t}=-k_{a} y \exp \left(\frac{E_{\mathrm{a}}}{R T_{\mathrm{d}}}\right)$

where $k_{\mathrm{a}}$ is a rate constant, $T_{\mathrm{d}}$ is the local temperature in the deposit, and the temperature sensitivity is given by $E_{\mathrm{a}}$.

Figure 4 shows how ageing can affect the thermo-hydraulic response of an exchanger to fouling. With no ageing, the thermal impact is mirrored by a hydraulic impact, so that a reduction in heat transfer is accompanied by an increase in pressure drop (for constant flow rate operation). Ageing changes this: in the case of slow ageing, the impact on heat transfer levels off while the hydraulic penalty continues to grow. With fast ageing (converting the layer into a high thermal conductivity 
Fig. 10 Evolution of a effective deposit thermal conductivity and b thermo-hydraulic performance in case study exchanger E6B for fast and slow ageing with strong temperature dependency (a)

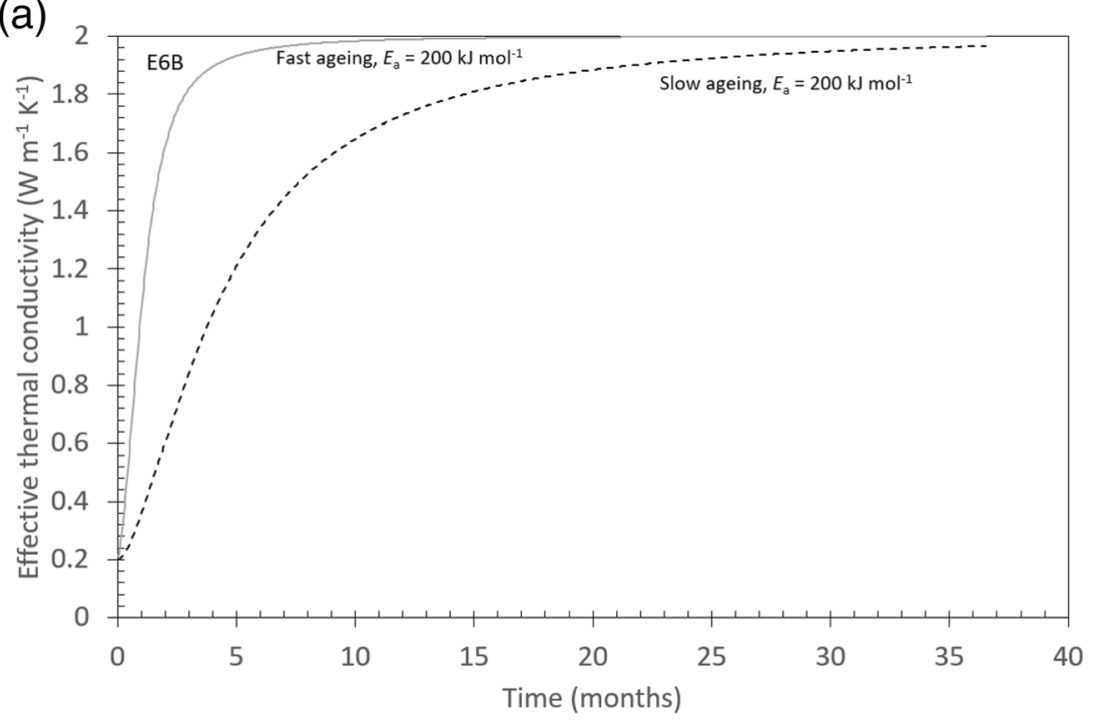

(b)

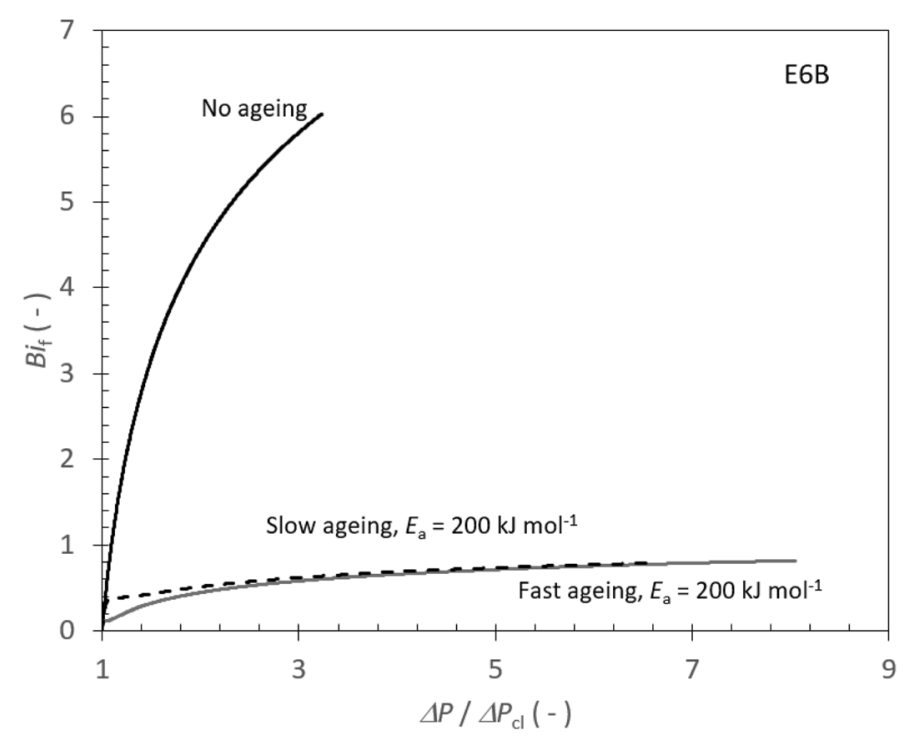

coating), the hydraulic penalty dominates. This makes interpretation of fouling data challenging, particularly as pressure drops are not measured as widely as heat transfer rates. More research needs to be done on this topic, a point made regularly by Graham Polley in his interrogation of conference presenters about the absence of pressure drop data in their papers.

Ageing is incorporated in the MTFP here by calculating $\lambda_{\mathrm{c}}$ at $t_{\mathrm{op}}$ and adjusting the $B i_{\mathrm{f}}$ and $\Delta P$ values accordingly. One could perform the calculations over a series of times and animate the MTFP to illustrate the dynamics: this could be readily incorporated in software tools.

\section{Case Study}

\section{Network Calculation}

The above concepts are demonstrated using a preheat train based on that presented by Panchal and Huang-Fu (2000) which has been used by several workers to illustrate fouling in CDUs. The network of 22 individual shells (Fig. 5) is not complicated as each hot stream is contacted with the crude once: in many refineries a hot stream can be involved in several matches, introducing feedback into the network performance (e.g. Ishiyama et al. 2009). The heat exchangers are 
Fig. 11 Combined effect of fouling and ageing on network performance, quantified by furnace inlet (i) temperature and (ii) pressure. Solid line - no ageing; dashed line—slow ageing; dotted line - fast ageing, for a weak temperature dependency and $\mathbf{b}$ strong temperature dependency (i)

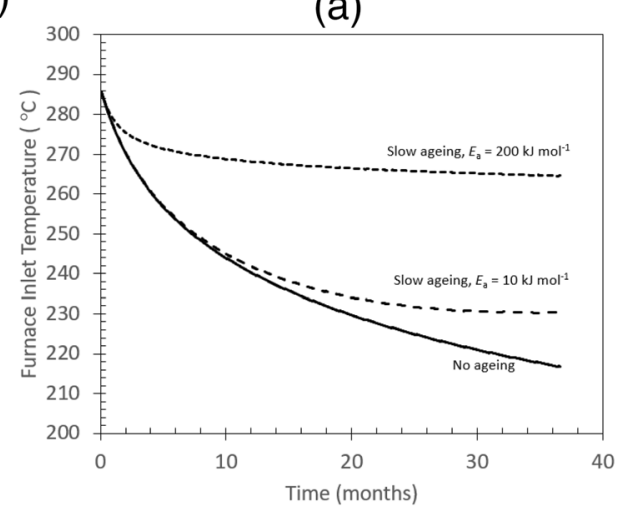

(ii)

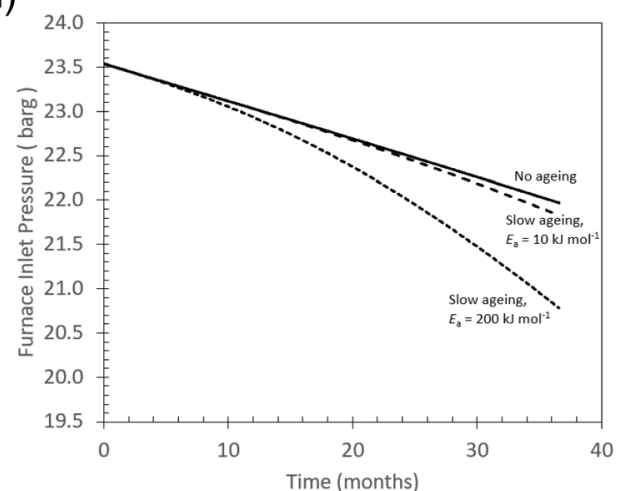

(b)
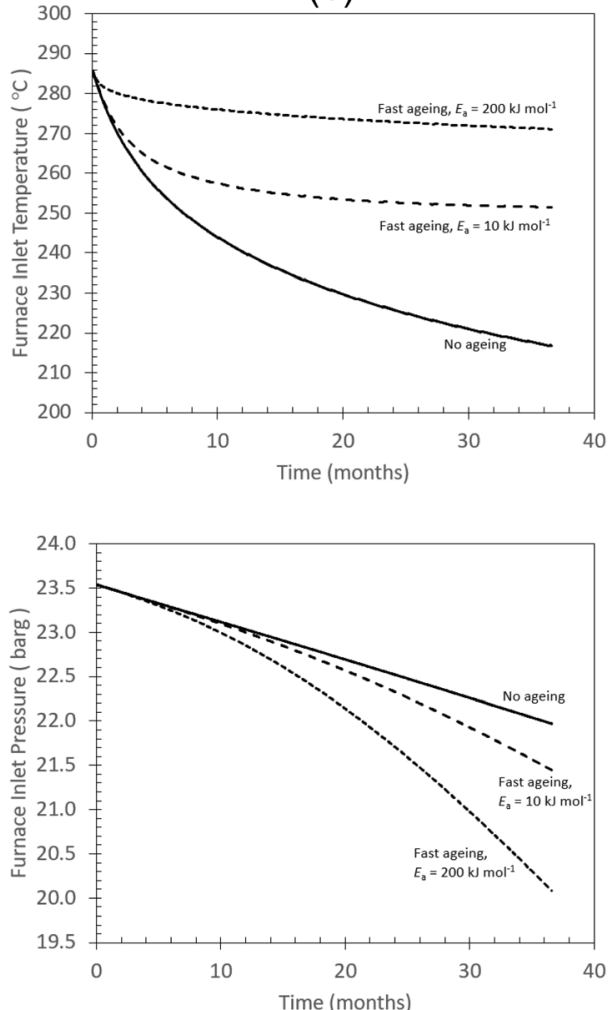

arranged in six groups: those in E2-E6 feature two sets in parallel, which allows one set to be cleaned while the network continues to operate. Scheduling of such cleaning operations is not considered in this study.

The individual exchanger geometries are summarised in Table 2. The stream inlet conditions (flow rates and temperatures) are taken from Panchal and Huang-Fu, except for some of the product stream temperatures which did not reflect those coming from a typical atmospheric column and have been replaced with more values which the authors consider to be more realistic (Table 3 ).

\section{Fouling Models}

Different fouling models were used to define fouling in different sections of the network. Upstream of the desalter, the exchangers were assumed to have constant fouling rates of $2 \times 10^{-8} \mathrm{~m}^{2} \mathrm{~K} \mathrm{~W}^{-1} \mathrm{~h}^{-1}$ (E1) and $4 \times 10^{-8} \mathrm{~m}^{2} \mathrm{~K} \mathrm{~W}^{-1} \mathrm{~h}^{-1}$ (E2). These differed from those in the Panchal and Huang-Fu paper. This level of fouling meant that the desalter inlet temperature could be maintained at the target temperature of $120{ }^{\circ} \mathrm{C}$ over the 3-year period, without resorting to cleaning upstream (see Ishiyama et al. 2010b).

Downstream of the desalter the asphaltene precipitation model (Eq. [7]) was used to model the dynamic fouling behaviour of the units in E3-E6, with $E_{\mathrm{f}}$ set at $44.3 \mathrm{~kJ} \mathrm{~mol}^{-1}$, $k_{\mathrm{f}, \mathrm{APM}}$ set at $50 \mathrm{~h}^{-1}$ (within the range reported in Ishiyama et al. (2014b)) and a critical wall shear stress of $2 \mathrm{~Pa}$, as above. This gives the fouling threshold relationship in Fig. 6, calculated for $h=1000 \mathrm{~W} \mathrm{~m}{ }^{-2} \mathrm{~K}^{-1}$, with negligible fouling taken as build-up less than $5 \times 10^{-4} \mathrm{~m}^{2} \mathrm{~K} \mathrm{~W}^{-1}$ over 2 years. The $\mathrm{x}$-axis is plotted in terms of wall shear stress rather than velocity, as this is the process parameter that appears in Eq. [7] (and $h$ is linked to $\left.\tau_{\mathrm{w}}\right) . \tau_{\mathrm{w}}$ can be calculated for each exchanger. The threshold temperatures are not high, so fouling is expected to occur throughout the network.

Figure 7 shows the MTFP calculated for the APM with the parameters given. The MTFP is constructed from the outputs of the calculation. Fouling threshold loci are plotted for shear stresses of 2 and $20 \mathrm{~Pa}$, spanning the tubeside shear stresses which arise in E3-E6. It should be noted that the loci appear as horizontal lines on the plot as the model is written in terms of the film temperature, and this is used on the left-hand y-coordinate. The units in the network are plotted as solid lines (thermal) and boxes (hydraulic) with the $\tau_{\mathrm{w}}$ values alongside.

It can be seen that exchangers E3 to E6 all lie above the fouling threshold. Moreover, all these units have low $\tau_{\mathrm{w}}$ values ( $<5 \mathrm{~Pa}$ when clean), so will encounter significant fouling, particularly E6 (with combination of low $\tau_{\mathrm{w}}$ and high $T_{\mathrm{f}}$ ). The fouling mechanism for exchangers E1 and E2 is not described by the APM and it is not relevant for the threshold fouling discussion. The main contributors to the pressure drop are E1 (low fouling), E3 (appreciable fouling) and E5 (heavy 
(a)

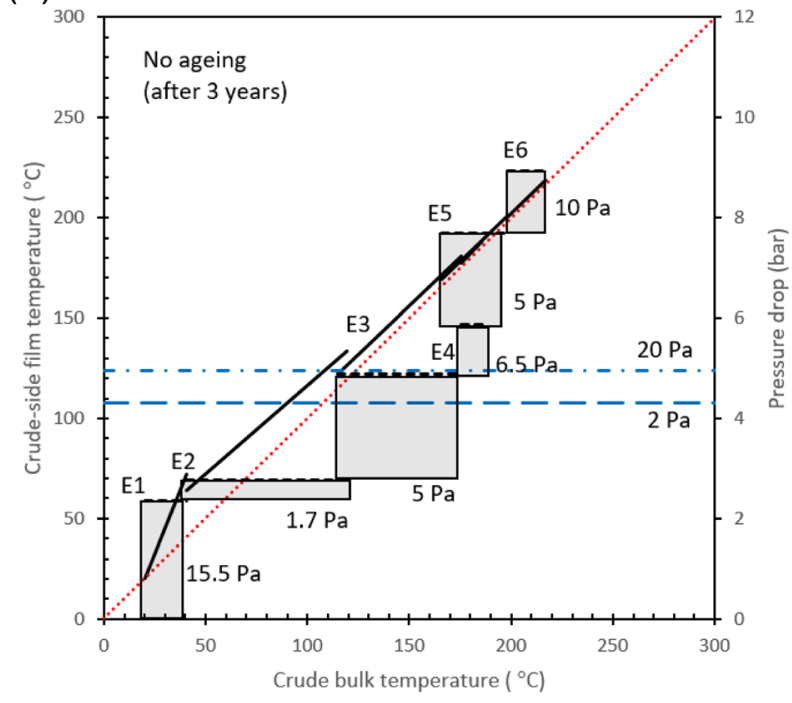

(c)

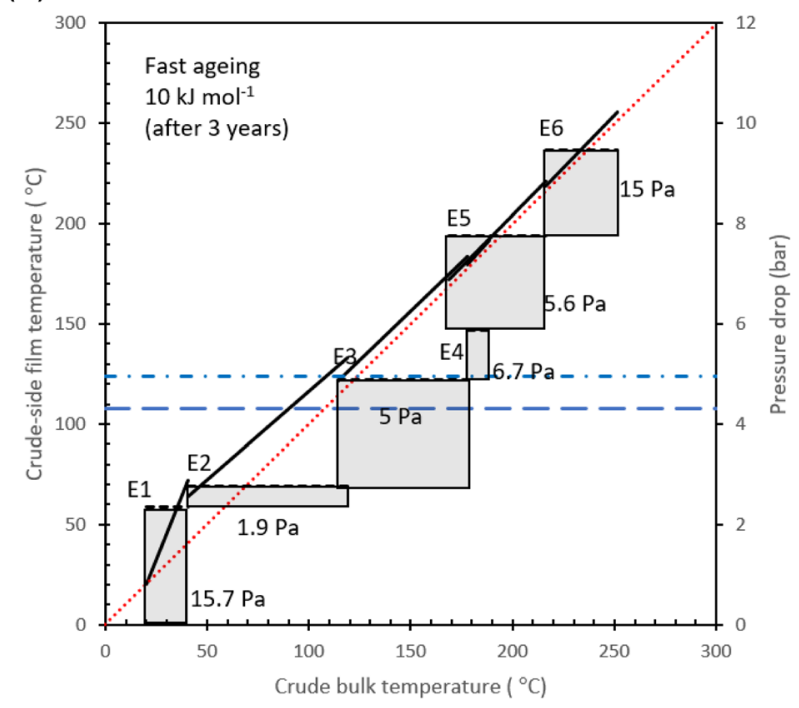

(b)

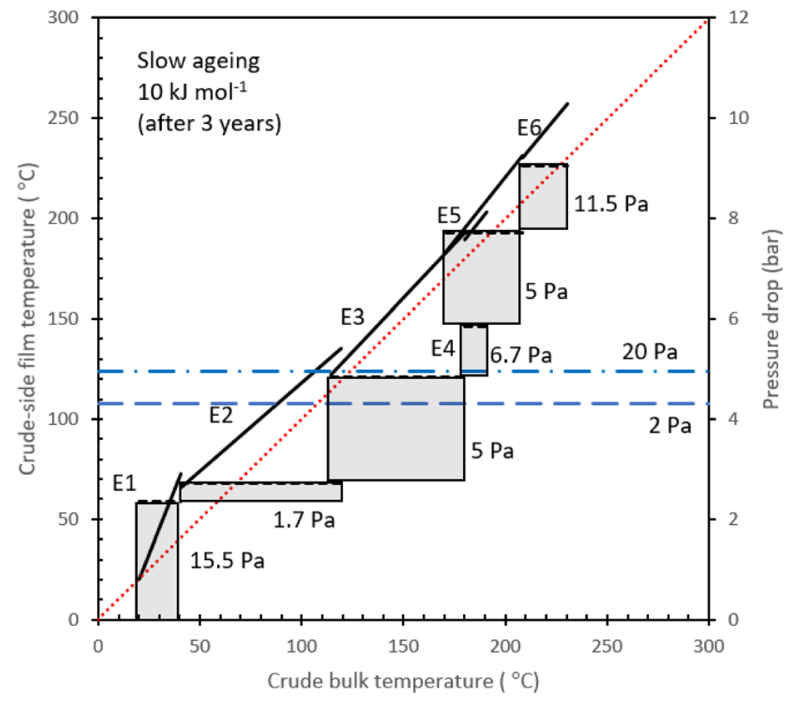

(d)

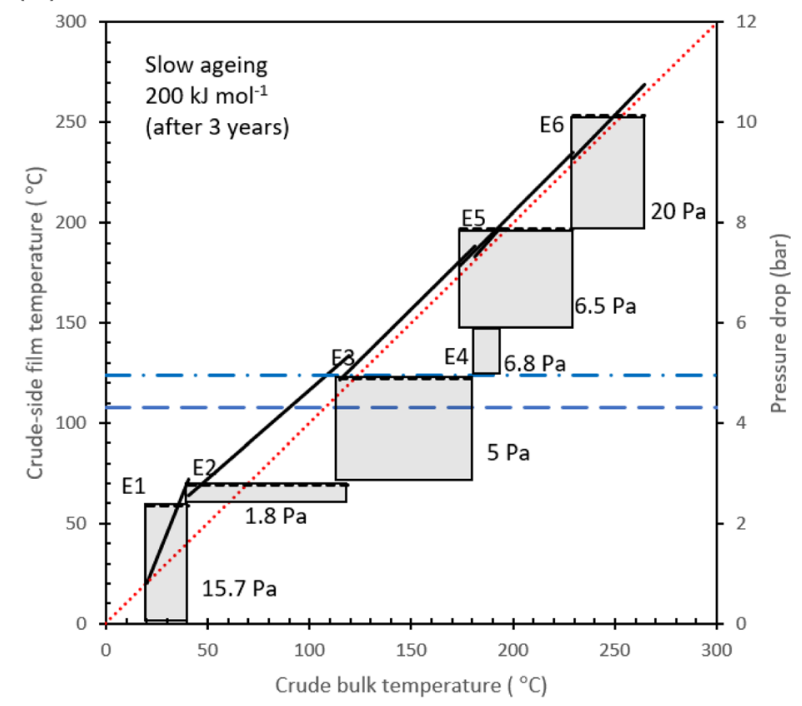

(e)

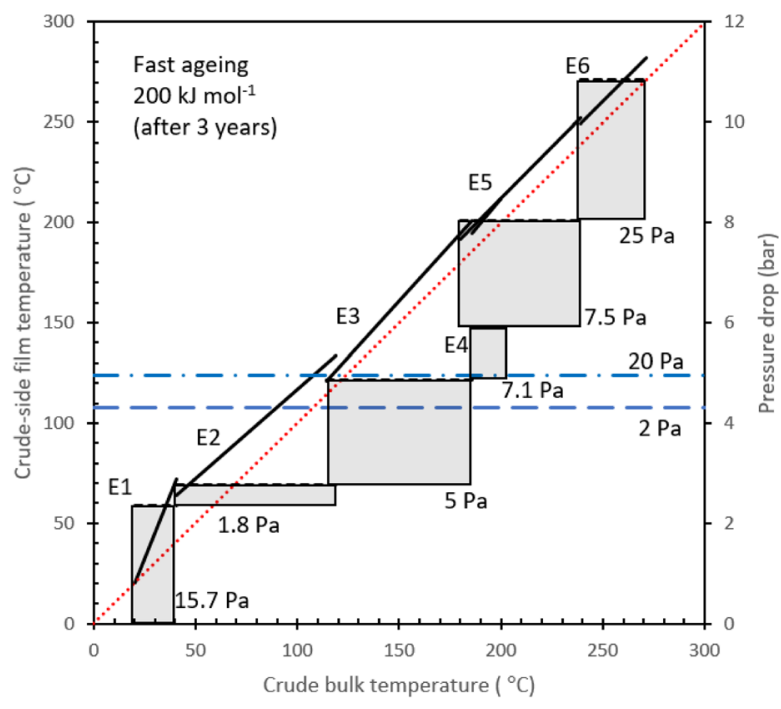


Fig. 12 Modified temperature field plot for the case study network when after 3 years with a no ageing; b slow ageing, weak temperature dependency; c slow ageing, strong temperature dependency; $\mathbf{d}$ fast ageing, weak temperature dependency; $\mathbf{e}$ fast ageing, strong temperature dependency

fouling), so the hydraulic impact of fouling will manifest strongly in E5 and possibly E6. Ageing is driven by surface temperature, so is expected to be more significant in E6 than E5.

All these points can be derived from the MTFP, illustrating its value in understanding the likely impacts of fouling. Wilson et al. (2002) describe how the MTFP could be used subsequently to consider mitigation by retrofitting the network. We focus here on the impact of ageing.

\section{Deposit Ageing Model}

The calculation approach presented by Ishiyama et al. (2010a) was implemented, where the deposit is treated as a series of thin layers laid down at time $t_{\mathrm{i}}$, initially with thermal conductivity $\lambda_{\mathrm{c}, 0}$, and which subsequently undergoes ageing determined on the local temperature, $T_{\mathrm{d}, \mathrm{i}}$. A schematic of the process is shown in Fig. 8. A detailed account of the calculation is given in Ishiyama et al. (2010a).

In the results presented here, the conditions in the network are calculated at intervals of length $\Delta t$ : the fouling and ageing rates are then revised, and the amount of fresh deposit laid down over the interval added to each exchanger. The effective (overall) thermal conductivity of the deposit, $\lambda_{\text {eff }}$, is calculated from

$\lambda_{\text {eff }}=\frac{\sum_{i=1}^{n} \delta_{i}}{\sum_{i=1}^{n} \frac{\delta_{i}}{\lambda_{i}}}$

$\delta_{\mathrm{l}}$ is the thickness of deposit layer $i$, calculated from $\delta_{\mathrm{i}}=\lambda_{0} \frac{d R_{\mathrm{f}, \mathrm{i}}}{d t} \Delta t$, and $n$ is the number of deposit layers deposited up to time $t$, given by $n(t)=t / \Delta t$. A $\Delta t$ value of 1 day is used here.

\section{Ageing Rate Constants}

Given the lack of experimental data available, a series of scenarios is considered, similar to the approach reported by Ishiyama et al. (2010c). These differed in terms of initial rate (under initial operating conditions), labelled 'fast' and 'slow', and temperature sensitivity (high and low). The deposit thermal conductivity varies from 0.2 to $2.0 \mathrm{~W} \mathrm{~m}^{-1} \mathrm{~K}^{-1}$. The sensitivity to temperature is quantified by $E_{\mathrm{a}}$ and two values are considered: (i) $10 \mathrm{~kJ} \mathrm{~mol}^{-1}$, which implies that to double the rate of reaction at the temperatures encountered at the hot end of this preheat train, the temperature would have to increase by approximately $200{ }^{\circ} \mathrm{C}$. This means that the ageing rate will be effectively independent of fouling.

(ii) $200 \mathrm{~kJ} \mathrm{~mol}^{-1}$, which implies high sensitivity to $T_{\mathrm{d}}$ : a roughly $5{ }^{\circ} \mathrm{C}$ increase in temperature would double the rate of reaction. The range of $E_{\mathrm{a}}$ from 10 to $200 \mathrm{~kJ} \mathrm{~mol}^{-1}$ is likely to cover the possible temperature kinetics experienced in a typical preheat train.

The scenarios are then

(i) Slow and low, with ageing rate constant $k_{\mathrm{a}, \text { slow,10 }}$ and $E_{\mathrm{a}}=10 \mathrm{~kJ} \mathrm{~mol}^{-1}$. The value used for $k_{\mathrm{a}, \text { slow, } 10}$ is $5 \times$ $10^{-5} \mathrm{~h}^{-1}$.

(ii) Fast and low, with $k_{\mathrm{a}, \text { fast,10 }}=10 k_{\mathrm{a}, \text { slow,10. }}$

(iii) Slow and high, with $k_{\mathrm{a}}$, slow, 200 $=k_{\mathrm{a}}$, slow, $10 \exp (22.85 /$ $T_{\mathrm{s}}$ ), compensating for the different temperature sensitivities.

(iv) Fast and high, with $k_{\mathrm{a}, \text { fast,200 }}=10 k_{\mathrm{a}, \text { slow,200. }}$

The effect of ageing in exchanger E6B over the 3-year operating period is shown in Figs. 9 and 10 for fast and slow ageing with two different temperature sensitivities, respectively. This unit features the highest crude and wall temperatures in the network and from the MTFP is expected to be subject to significant fouling. It is immediately upstream of the furnace so loss in heat transfer in E6B (and E6A) has a direct impact on network performance in terms of energy recovery. Figure 9a shows that fast ageing results in the effective thermal conductivity changing noticeably over time, even with a weak temperature dependency. There is little change in $\lambda_{\text {eff }}$ for slow ageing. Figure $9 \mathrm{~b}$ shows that fouling is significant in this unit (as expected from the MTFP): $B i_{\mathrm{f}}$ reaches 6 and $\Delta P / \Delta P_{\mathrm{cl}}$ exceeds 3 after 3 years in the absence of ageing. The slow ageing case shows significant thermal and hydraulic impacts $\left(B i_{\mathrm{f}} \rightarrow 4, \Delta P / \Delta P_{\mathrm{cl}} \rightarrow 4\right)$, with some recovery in heat transfer later on accompanied by increasing pressure drop.

Fast ageing results in $B i_{\mathrm{f}}$ reaching a plateau value of $\sim 1$ early on, while $\Delta P / \Delta P_{\mathrm{cl}}$ continues to increase. In this scenario, the fouling dynamics would be masked in any monitoring based on thermal performance alone. This behaviour arises from the higher thermal conductivity of the deposit causing the surface temperature of the deposit to decrease less as a result of fouling, keeping the fouling rate high. A thicker fouling deposit is then generated, narrowing the flow path and increasing the pressure drop across the exchanger, by over $100 \%$.

The fast ageing behaviour in Fig. 9 is reproduced in Fig. 10, where the increased temperature sensitivity of ageing drives a faster increase in $\lambda_{\text {eff. }} B i_{\mathrm{f}}$ reaches a plateau value of approximately 0.5 , representing a small impact on thermal 
performance, while $\Delta P / \Delta P_{\mathrm{cl}} \rightarrow 6$ (slow ageing) and 8 (fast ageing). Such hydraulic losses are unlikely to be acceptable, and the simple hydraulic impact model is unlikely to be valid with a very thick deposit.

The corresponding plots for the other units in the network are provided in the Supplementary Information. These show similar trends to Fig. 9, with smaller and slower changes as a result of the lower temperatures in these units.

\section{Network Performance}

When clean, the crude entered the furnace at a temperature of $285^{\circ} \mathrm{C}$ and pressure of 23.5 bar. Figure 11 shows the furnace inlet temperature (FIT) and pressure (FIP) profiles over 3-year operation without cleaning. In the absence of ageing, the inlet temperature and pressure fall steadily to $217^{\circ} \mathrm{C}$ and 22 bar, respectively. The desalter temperature (not shown) stayed within its allowed range. While the change in pressure is modest, the reduction in FIT by nearly $70 \mathrm{~K}$ is unlikely to be acceptable and would require cleaning or a revamp of the network. In this regard, the MTFP becomes a useful tool because it indicates where the changes in thermal and hydraulic performance arise, and how the affected units relate to the fouling threshold.

Ageing improves heat transfer through the deposit (although it can also increase the amount deposited) and all the ageing scenarios result in a smaller change in FIT, and a greater reduction in FIP. In the fastest ageing scenario (fast ageing, $E_{\mathrm{a}}=200 \mathrm{~kJ} \mathrm{~mol}^{-1}$ ), FIT falls to $271^{\circ} \mathrm{C}$ and FIP to $20 \mathrm{bar}$. If monitoring temperature alone, it would not be possible to identify the hydraulic impact until an operational problem arose (such as the pumping capacity being reached and the crude boiling). The need for pressure drop measurements to help elucidate the actual performance of the network when subject to fouling and ageing is clear.

FIT and FIP constitute overall measures of the network performance. The impact of fouling and ageing within the network is conveniently presented in the MTFPs in Fig. 12. The change in heat transfer is communicated by the change on the $T_{\mathrm{b}}$ scale while the change in pressure drop is marked by the height of the boxes and the $\tau_{\mathrm{w}}$ values. Figure 12 a shows the state after 3 years with no ageing. Comparing this with Fig. 7 , the change in FIT is evident, with only modest increases in $T_{\mathrm{b}}$ in E4, E5 and E6. The changes in pressure drop are across E5 and E6. Although the FIP is lower, the reduction in $T_{\mathrm{b}}$ in E6 may mean that vapourisation is avoided in this unit. However, the large reduction in FIT is likely to violate a furnace firing limit. Fouling mitigation measures are needed.

The impact of fouling on individual heat exchangers, and interactions between units, can be gauged from the change in size of the boxes in Figs. 7 and 12. More detailed inspection can then be performed on the data used to construct the plots. The interactions can also be studied systematically using the network analysis techniques presented by Picón-Núñez and Polley (1995a, b).

Slow ageing (Fig. 12b, c) shows smaller pressure drop increases in E5 and E6, accompanying increased duties in these units compared to the no ageing case. Comparing the MTFPs with that in Fig. 7 again highlights where fouling, now with ageing, is causing the largest operating penalties. The MTFPs for the fast ageing scenarios (Fig. 12d, e) show how large pressure drops arise in E5 and E6 with only small impacts on overall heat transfer, arising from the fouling rate staying high as a result of the deposit thermal conductivity quickly approaching that of a coke. The low absolute pressure in E6 is accompanied by a high $T_{\mathrm{b}}$, which is likely to result in vapourisation. Moreover, the high pressure drop is likely to lead to reduced throughput as a result of the pump characteristics. This will have a direct impact on the production margin as preheat train operation economics are strongly affected by throughput. Reduction in flow rate will also change the heat transfer characteristics (and surface temperatures) in the system, which the analysis would need to incorporate if these features were to be included. These are routinely calculated in modern CDU simulation tools.

These aspects of contrary thermo-hydraulic impacts arising from ageing were not considered by Polley and his co-workers when creating the MTFP. The case study demonstrates that the construction is able to visualise these quite effectively, so the designer or operator can see where fouling is likely to occur and how big an effect it will have on the network. Approaches for revamping and retrofitting preheat trains based on MTFPs have been presented in Yeap et al. (2003) and Wilson et al. (2005): the reader is referred to these earlier contributions from Graham Polley and co-workers rather than reproducing the material here.

\section{Conclusions}

Fouling is a chronic operating problem in the oil refining sector and is expected to continue to pose problems in future. Understanding the impact of fouling on the thermal and hydraulic performance of heat exchangers subject to fouling can be aided by the use of visualisation tools such as the modified temperature field plot introduced by Polley and co-workers. This construction has been modified here to include considerations of deposit ageing, using a simple ageing model in a case study based on a simple preheat train network. The shifting of the balance between thermal and hydraulic impacts of fouling caused by ageing is found to propagate into the network performance. The modified temperature field plot is shown to be an effective way to present the results of detailed analysis for the network designer or operator to gauge the contribution from the different factors involved. This demonstrates the 
need to monitor pressure drops in preheat trains subject to fouling, and to analyse the operating data carefully.

Acknowledgements Many of the ideas presented here were birthed and refined during discussions between the authors and Dr. Graham Polley when authors EMI and SJP were at IHS Downstream Research.

\section{Nomenclature}

Roman $\quad b$, exponent, Eq. [6], $\mathrm{m}^{2} \mathrm{~K} \mathrm{~Pa}^{-1} \mathrm{~J}^{-1} ; B i_{\mathrm{f}}$, fouling Biot number, -; $c$, exponent, Eq. [7], $\mathrm{Pa} ; d_{\mathrm{i}}$, tube inner diameter, $\mathrm{m} ; E_{\mathrm{a}}$, activation energy for ageing, $\mathrm{J} \mathrm{mol}^{-1} ; E_{\mathrm{f}}$, activation energy for deposition, $\mathrm{kJ} \mathrm{mol}^{-1} ; h$, film heat transfer coefficient, $\mathrm{W} \mathrm{m}^{-2} \mathrm{~K}^{-1} ; k_{\mathrm{a}}$, ageing kinetic parameter, $\mathrm{s}^{-1} ; k_{\mathrm{f}}$, deposition rate constant, $\mathrm{m}^{2-\mathrm{m}} \mathrm{K} \mathrm{W}^{-1} \mathrm{~s}^{\mathrm{m}} ; k_{\mathrm{f}, \mathrm{APM}}$, deposition rate constant, Eq. [7], $\mathrm{s}^{-1} ; m$, exponent, Eq. [6], $-; n$, number of deposit layers, $-; \Delta P$, pressure drop, $\mathrm{Pa} ; \Delta P_{\mathrm{cl}}$, pressure drop when clean, $\mathrm{Pa} ; \Delta P^{*}$, dimensionless pressure drop, $-; R$, gas constant, $\mathrm{J} \mathrm{mol}^{-1} \mathrm{~K}^{-1} ; R_{\mathrm{f}}$, fouling resistance, $\mathrm{m}^{2} \mathrm{~K} \mathrm{~W}^{-1} ; t$, time, $\mathrm{s} ; t_{\mathrm{op}}$, operating interval, $\mathrm{s} ; T$, temperature, $\mathrm{K} ; T_{\mathrm{b}}$, bulk temperature, $\mathrm{K} ; T_{\text {cold }}$, bulk crude temperature, $\mathrm{K} ; T_{\mathrm{d}}$, deposit temperature, $\mathrm{K} ; T_{\mathrm{f}}$, film temperature, $\mathrm{K} ; T_{\mathrm{s}}$, surface temperature, $\mathrm{K} ; U_{\mathrm{o}}$, overall heat transfer coefficient (clean), $\mathrm{W} \mathrm{m}^{-2} \mathrm{~K}^{-1} ; U$, overall heat transfer coefficient, $\mathrm{W} \mathrm{m}^{-2} \mathrm{~K}^{-1} ; v$, mean flow velocity, $\mathrm{m} \mathrm{s}^{-1} ; y$, ageing variable (youth factor), -

Greek $\delta$, deposit thickness, $\mathrm{m} ; \lambda_{\mathrm{c}}$, deposit thermal conductivity, $\mathrm{W} \mathrm{m}{ }^{-1} \mathrm{~K}^{-1} ; \lambda_{\mathrm{c}, 0}$, thermal conductivity, fresh deposit, $\mathrm{W} \mathrm{m}{ }^{-1} \mathrm{~K}^{-1} ; \lambda_{\mathrm{c}}$, thermal conductivity, coked deposit, $\mathrm{W} \mathrm{m}^{-1} \mathrm{~K}^{-1} ; \lambda_{\text {eff }}$, effective thermal conductivity, composite deposit, $\mathrm{W} \mathrm{m}^{-1} \mathrm{~K}^{-1} ; \tau_{\mathrm{w}}$, wall shear stress, $\mathrm{Pa}$

Open Access This article is licensed under a Creative Commons Attribution 4.0 International License, which permits use, sharing, adaptation, distribution and reproduction in any medium or format, as long as you give appropriate credit to the original author(s) and the source, provide a link to the Creative Commons licence, and indicate if changes were made. The images or other third party material in this article are included in the article's Creative Commons licence, unless indicated otherwise in a credit line to the material. If material is not included in the article's Creative Commons licence and your intended use is not permitted by statutory regulation or exceeds the permitted use, you will need to obtain permission directly from the copyright holder. To view a copy of this licence, visit http://creativecommons.org/licenses/by/4.0/.

\section{References}

Brahim F, Augustin W, Bohnet M (2003) Numerical simulation of the fouling process, Intl. J Therm Sci 42(3):33-334

Brown ARG, Watt W, Powell RW, Tye RP (1956) The thermal and electrical conductivities of deposited carbon. Br J Appl Phys 7:7376. https://doi.org/10.1088/0508-3443/7/2/309

Coletti F, Ishiyama EM, Paterson WR, Wilson DI, Macchietto S (2010) Impact of deposit ageing and surface roughness on thermal fouling: distributed model. AIChEJ 56(12):3257-3273

Coletti F, Macchietto S, Polley GT (2011) Effects of fouling on performance of retrofitted heat exchanger networks: a thermo-hydraulic based analysis. Computers Chem Eng. 35(5):907-917

Davies TJ, Henstridge S, Gillham CR, Wilson DI (1997) Investigation of milk fouling deposit properties using heat flux sensors. Food Bioprod Process 75:106-110

Derakshesh M, Eaton P, Newman B, Hoff A, Mitlin D, Gray MR (2013) Effect of asphaltene stability on fouling at delayed coking process furnace conditions. Energy Fuel 27(4):1856-1864
Diaby AL, Miklavcic SJ, Bari S, Addai-Mensah J (2016) Evaluation of crude oil heat exchanger network fouling behavior under aging conditions for scheduled cleaning. Heat Transfer Eng 37(15):12111230

Diaz-Bejarano E, Coletti F, Macchietto S (2016) A new dynamic model of crude oil fouling deposits and its application to the simulation of fouling-cleaning cycles. AIChEJ. 62:90-107

Ebert W, Panchal CB (1997) Analysis of Exxon crude-oil slip stream coking data. In: Panchal CB, Bott TR, Somerscales EFC, Toyama $\mathrm{S}$ (eds) Fouling mitigation of industrial heat exchange equipment. Begell House, New York, pp 451-460

Evans, A. (1968) Fouling characteristics of ASTM jet A fuel when heated to 700 deg $\mathrm{F}$ in a simulated heat exchanger tube. Technical report NASA TN D-4958. NASA

Fan Z, Watkinson AP (2006) Formation and characteristics of carbonaceous deposits from heavy hydrocarbon coking vapors. Ind Eng Chem Res 45(19):6428-6435

Fan, Z. (2006) Formation and characteristics of carbonaceous deposits from heavy hydrocarbon vapours. PhD Dissertation, University of British Columbia, Vancouver, Canada, https://doi.org/10.14288/1. 0058724

Güralp OA (2008) The effect of combustion chamber deposits on heat transfer and combustion in a homogeneous charge compression ignition engine (PhD Thesis). University of Michigan, Ann Arbor

Ishiyama EM, Paterson WR, Wilson DI (2009) A platform for technoeconomic analysis of fouling mitigation options in refinery preheat trains. Energy Fuels 23(3):1323-1337

Ishiyama EM, Coletti F, Machietto S, Paterson WR, Wilson DI (2010a) Impact of deposit ageing on thermal fouling. AIChEJ 56(2):531545

Ishiyama EM, Heins AV, Paterson WR, Spinelli L, Wilson DI (2010b) Scheduling cleaning in a crude oil preheat train subject to fouling: incorporating desalter control. Appl Thermal Eng 30:1852-1862

Ishiyama EM, Paterson WR, Wilson DI (2010c) Exploration of alternative models for the ageing of fouling deposits. AIChEJ 57(11): 3199-3209

Ishiyama, E.M., Pugh, S.J., Wilson, D.I., Paterson, W.R., Polley, G.T. (2011) Importance of data reconciliation on improving performances of crude refinery preheat trains, in Proc. AIChE Annual Meeting, Conference Proceedings. Presented at the 7th Global Congress on AIChE Process Safety conference, Chicago

Ishiyama, E.M., Polley, G.T., Pugh, S.J. (2012a) Recent experiences on modelling fouling of crude refinery preheat trains handling complex and heavy crude slates, in Proc AIChE Annual Meeting

Ishiyama, E.M., Pugh, S.J., Polley, G.T., Wilson, D.I. (2012b) Industrial experience in handling cleaning of crude refinery preheat trains, in Proc AIChE Annual Meeting

Ishiyama, E.M., Pugh, S.J., Kennedy, J., D.I. Wilson, Ogden-Quin A., Birch, G. (2013) An industrial case study on retrofitting heat exchangers and revamping preheat trains subject to fouling, Proc Intl. Conf. Heat Exchanger Fouling and Cleaning, http:// heatexchanger-fouling.com/papers/papers2013/05_Pugh_F.pdf

Ishiyama EM, Paterson WR, Wilson DI (2014a) Ageing is important: closing the fouling-cleaning loop. Heat Transfer Eng 35(3):311-326

Ishiyama E, Kennedy J, Pugh SJ (2014b) Scopes for improvements on preheat trains of crude refineries subject to fouling. Presented at the 17th Topical on Refinery Processing 2014 -Topical Conference at the 2014 AIChE Spring Meeting and 10th Global Congress on Process Safety, pp. 492-505

Ishiyama EM, Pugh SJ (2015) Considering in-tube crude oil boiling in assessing performance of preheat trains subject to fouling, Heat Transfer Engineering 36:632-641

Ishiyama EM, Falkeman E, Wilson ID, Pugh SJ (2020) Quantifying implications of deposit aging from crude refinery preheat train data. Heat Transfer Eng 41(2):138-148

Kern DQ (1957) Process heat transfer. McGraw-Hill, New York 
Kumana, J.D., Polley, G.T., Pugh, S.J., Ishiyama, E.M. (2010) Improved energy efficiency in CDUs through fouling control, in Proc. AIChE Spring Meeting. San Antonio, Texas, paper no. 99a

Liu L-L, Fan J, Chen P-P, Du J (2015) Synthesis of heat exchanger networks considering fouling, aging, and cleaning. Ind Eng Chem Res 54(1):296-306

Maksimovskii VV, Raud ÉA, Sokolov OA, Korsak IV, Chepovskii MA (1990) Thermal conductivity of coke deposited in quenchingevaporative equipment of pyrolysis units. Chem Technol Fuels Oils 26:584-587

Mayhew E, Prakash V (2013) Thermal conductivity of individual carbon nanofibers. Carbon 62:493-500. https://doi.org/10.1016/j.carbon. 2013.06.048

Mohanty, D.K. (2012) Estimation and prediction of fouling behaviour in a shell and tube heat exchanger. $\mathrm{PhD}$ thesis, Birla Institute of Technology and Science, Pilani (Rajasthan)

Morales-Fuentes, A., Rodriguez, G.M., Polley, G.T., Picon-Nunez, M., Ishiyama, E.M., (2011) Simplified analysis of influence of preheat train performance and fired heater design on fuel efficiency of fired heaters. Proc. 9th International Conference on Heat Exchanger Fouling and Cleaning, Crete, Greece

Nelson WL (1939) Fouling of heat exchangers. Refiner \& Natural Gasoline Manufacturer 13(7):271-276

Panchal CB, Huang-Fu EP (2000) Effects of mitigating fouling on the energy efficiency of crude-oil distillation. Heat Transfer Eng 21:3-9

Perry RH, Green DW (2007) Perry's chemical engineers' handbook. McGraw-Hill

Picón-Núñez M, Polley GT (1995a) Determination of the steady-state response of heat-exchanger networks without simulation. Chem Eng Res Des 73:49-58

Picón-Núñez M, Polley GT (1995b) Applying basic understanding of heat exchanger network behaviour to the problem of plant flexibility. Chem Eng Res Des 73:941-952

Polley GT, Wilson DI, Yeap BL, Pugh SJ (2002a) Use of crude oil threshold data in heat exchanger design. Appl Therm Eng 22:763-776

Polley GT, Wilson DI, Yeap BL, Pugh SJ (2002b) Evaluation of laboratory crude oil fouling data for application to refinery pre-heat trains. Appl Therm Eng 22:777-788

Polley, G.T., Wilson, D.I., Petitjean, E. and Derouin, C. (2005) The fouling limit in crude oil pre-heat train design, Hydrocarbon Processing, July, $71-80$

Polley GT, Wilson DI, Pugh SJ, Petitjean E (2007) Extraction of crude oil fouling model parameters from plant exchanger monitoring. Heat Transfer Eng 28(3):185-192

Polley, G.T., Morales-Fuentes, A., Wilson, D.I., (2009) Simultaneous consideration of flow and thermal effects of fouling in crude oil preheat trains, Heat Transfer Engineering 30(10-11):815-821

Polley, G.T., Tamakloe, E., Ishiyama, E., Pugh, S.J. (2011a) Analysis of plant data, in Proc. 11AIChE-2011 AIChE Spring Meeting and 7th Global Congress on Process Safety
Polley, G.T., Wilson, D.I., Ishiyama, E. (2011b) Mitigation of fouling in pre-heat trains, in: Proc. AIChE—2011 AIChE Spring Meeting and 7th Global Congress on Process Safety, Chicago

Polley GT, Tamakloe E, Picon Nunez M, Ishiyama EM, Wilson DI (2013) Applying thermo-hydraulic simulation and heat exchanger analysis to the retrofit of heat recovery systems. Appl Therm Eng 51:137143

Robinson AL, Buckley SG, Baxter LL (2001) Experimental measurements of the thermal conductivity of ash deposits: part 1 . Measurement technique. Energy Fuels 15:66-74. https://doi.org/ $10.1021 / \mathrm{ef000036c}$

Rodriguez C, Smith R (2007) Optimization of operating conditions for mitigating fouling in heat exchanger networks. Chem Eng Res Des 85(6):839-851

Watkinson AP (1988) Critical review of organic fluid fouling: final repot, ANL/CNSV-TM-208. American National Laboratory I11

Watkinson AP, Wilson DI (1997) Chemical reaction fouling: a review. Exptl Therm Fluid Sci 14:361-374

Weidenlener A, Pfeil J, Kubach H, Koch T, Forooghi P, Frohnapfel B, Magagnato F (2018) The influence of operating conditions on combustion chamber deposit surface structure, deposit thickness and thermal properties. Automot Eng Technol 3:111-127. https://doi. org/10.1007/s41104-018-0030-3

Wilson DI, Polley GT, Pugh SJ (2002) Mitigation of crude oil preheat train fouling by design. Heat Transfer Eng 23:24-37

Wilson, D.I., Polley, G.T. and Pugh, S.J. (2005) Ten years of EbertPanchal and the 'threshold fouling' concept, in Proc. 6th International Conference on Heat Exchanger Fouling and Cleaning - Challenges and Opportunities, Kloster Irsee, Germany

Wilson, D.I., Ishiyama, E.M., Paterson, W.R. and Watkinson, A.P. (2009) Ageing: looking back and looking forward, Proc Intl. Heat Exchanger Fouling Cleaning VIII, http://www.heatexchangerfouling.com/papers/papers2009/32_Wilson_\%20Ageing_F.pdf

Wilson DI, Ishiyama EM, Polley GT (2017) Twenty years of Ebert and Panchal - what next? Heat Transfer Eng 38(7-8):669-680

Yeap, B.L.,Wilson, D.I., Polley, G.T. and Pugh, S.J. (2003) Retrofitting crude oil refinery heat exchanger networks to minimise fouling while maximising heat recovery, in Proc. 5th International Conference on Heat Exchanger Fouling and Cleaning: Fundamentals and Application, Santa Fe, New Mexico, USA

Yeap BL, Wilson DI, Polley GT, Pugh SJ (2004) Mitigation of crude oil refinery heat exchanger fouling through retrofits based on thermohydraulic fouling models. Chem Eng Res Des 82A:53-71 [erratum $84 \mathrm{~A}, 248]$

Publisher's Note Springer Nature remains neutral with regard to jurisdictional claims in published maps and institutional affiliations. 